\title{
Human Papillomaviruses and genital co-infections in gynaecological outpatients
}

\author{
Rosita Verteramo ${ }^{1}$, Alessandra Pierangeli ${ }^{2}$, Emanuela Mancini ${ }^{1}$, \\ Ettore Calzolari1 ${ }^{1}$, Mauro Bucci ${ }^{2}$, John Osborn ${ }^{3}$, Rosa Nicosia ${ }^{4}$, \\ Fernanda Chiarini ${ }^{4}$, Guido Antonelli ${ }^{2}$ and Anna Marta Degener*2
}

\author{
Address: ${ }^{1}$ Department of Gynaecology, Perinatology and Child Health, "Sapienza" University of Rome, Italy, ${ }^{2}$ Department of Experimental \\ Medicine, Section of Virology, "Sapienza" University of Rome, Italy, ${ }^{3}$ Department of Public Health, "Sapienza" University of Rome, Italy and \\ ${ }^{4}$ Department of Public Health, Section of Microbiology, "Sapienza" University of Rome, Italy \\ Email: Rosita Verteramo - rositaverte@libero.it; Alessandra Pierangeli - alessandra.pierangeli@uniroma1.it; \\ Emanuela Mancini - e.mancini@libero.it; Ettore Calzolari - ettore.calzolari@uniroma1.it; Mauro Bucci - mauro.bucci@uniroma1.it; \\ John Osborn - john.osborn@uniroma1.it; Rosa Nicosia -rosa.nicosia@uniroma1.it; Fernanda Chiarini - fernanda.chiarini@uniroma1.it; \\ Guido Antonelli - guido.antonelli@uniroma1.it; Anna Marta Degener* - annamarta.degener@uniroma1.it \\ * Corresponding author
}

Published: 12 February 2009

BMC Infectious Diseases 2009, 9:16 doi:10.1/86/1471-2334-9-16
Received: 12 August 2008

Accepted: 12 February 2009

This article is available from: http://www.biomedcentral.com/I47/-2334/9/16

(c) 2009 Verteramo et al; licensee BioMed Central Ltd.

This is an Open Access article distributed under the terms of the Creative Commons Attribution License (http://creativecommons.org/licenses/by/2.0), which permits unrestricted use, distribution, and reproduction in any medium, provided the original work is properly cited.

\begin{abstract}
Background: High grade HPV infections and persistence are the strongest risk factors for cervical cancer. Nevertheless other genital microorganisms may be involved in the progression of HPV associated lesions.

Methods: Cervical samples were collected to search for human Papillomavirus (HPV), bacteria and yeast infections in gynaecologic outpatients. HPV typing was carried out by PCR and sequencing on cervical brush specimens. Chlamydia trachomatis was identified by strand displacement amplification (SDA) and the other microorganisms were detected by conventional methods.

Results: In this cross-sectional study on 857 enrolled outpatients, statistical analyses revealed a significant association of HPV with C. trachomatis and Ureaplasma urealyticum (at high density) detection, whereas no correlation was found between HPV infection and bacterial vaginosis, Streptococcus agalactiae, yeasts, Trichomonas vaginalis and $U$. urealyticum. Mycoplasma hominis was isolated only in a few cases both in HPV positive and negative women and no patient was infected with Neisseria gonorrhoeae.

Conclusion: Although bacterial vaginosis was not significantly associated with HPV, it was more common among the HPV positive women. A significant association between HPV and $C$. trachomatis was found and interestingly also with $U$. urealyticum but only at a high colonization rate. These data suggest that it may be important to screen for the simultaneous presence of different microorganisms which may have synergistic pathological effects.
\end{abstract}

\section{Background}

Infection with high grade Human papillomavirus (HPV) plays a central role in cervical carcinogenesis. Epidemio- logical and molecular investigations have shown unequivocally that high grade HPV infection is the main causal factor in initiating the progressive transformation 
that leads to cervical intraepithelial neoplasia and to cervical cancer $[1,2]$. Many reports have demonstrated that HPV infections are mostly transitory and that only a small percentage of infections persist and may progress to dysplastic cervical lesions: type-specific HPV persistence is the strongest risk factor for cervical cancer [3]. The reasons for the variable natural history remain poorly understood but it has been generally accepted that different cofactors are involved in the development of dysplasia in HPV infected women. Factors, such as specific HPV genotype, viral load, and co-infection with more HPV types, are likely to be involved in the progression to precancerous cervical lesions [4-6]. In addition, environmental factors [7-9] including smoking, long term hormone contraceptives and co-infection with other microorganisms have also been investigated as potentially involved in the disease process. The sexually transmitted agents that have shown some evidence of an association with cervical dysplastic and neoplastic lesion are Chlamydia trachomatis [10] and Herpes simplex virus (HSV) $[11,12]$, although the specific role of these microorganisms in the pathogenesis of cervical cancer has not been completely clarified.

The aim of this cross-sectional study was to evaluate the prevalence of co-infection HPV and other genital microorganisms: Chlamydia trachomatis, Neisseria gonorrhoeae, Streptococcus agalactiae, Mycoplasma spp, Trichomonas vaginalis. Yeasts and bacterial vaginosis were also investigated.

\section{Methods}

\section{Study population}

Women attending clinics for routine gynaecologic care in the Department of Gynaecology, Perinatology and Child Health of "Sapienza" University in Rome, between 2000 and 2006 were included in this study. Informed consent was obtained from all women and this study was approved by the Ethics Committees and/or Institutional Review Boards of the participating institution. Cervical samples were taken by cytobrush from the ectocervix and from the endocervix for cytological analysis, detection of HPV DNA and bacteriological tests. Cytology was classified according to the Bethesda system, using standard forms and classified as negative, atypical squamous cell of undetermined significance (ASCUS), atypical glandular cell of undetermined significance (AGUS), low-grade intraepithelial lesion (LSIL) or high-grade (HSIL) categories [13]. All the samples were analysed independently by two cyto-technologists and the final diagnosis was based on the consensus of both. Women were eligible for the study if they: were not currently pregnant nor planning to become pregnant for a year; had an intact uterus and no current referral for hysterectomy; reported no use of vaginal medication in the previous 3 days; reported no treatment for cervical disease in the previous 6 months; answered a structured questionnaire on socio-demo- graphic characteristics, sexual behaviour, reproductive history and smoking habits; provided samples adequate for PCR assays and sequencing. According to these criteria, 857 women were enrolled in this cross-sectional study.

\section{HPV detection and typing}

Cervical brush samples collected in Phosphate Saline Buffer (PBS) were centrifuged at low speed and the cell pellets underwent DNA extraction using QIAampTissue kit (Qiagen, Milan-Italy). Human Leukocyte Antigen (HLA)-specific primers were used in polymerase chain reaction (PCR) analysis to assess the suitability of the target DNA (9). A 450 bp fragment from the $\mathrm{L} 1$ region of HPV-DNA was amplified using the consensus primer MY09/11 as described elsewhere [14]. Four pairs of degenerated consensus primers (able to detect $36 \mathrm{HPV}$ types) were used concomitantly to amplify the complete E6 gene and part of the E7 gene [15], thus allowing the detection of a broader range of HPV genotypes. The PCR products were detected by ethidium bromide staining after electrophoretic migration through $2 \%$ agarose gels.

HPV-positive reactions were purified using a QIAquick PCR purification kit (QIAGEN), and an automatic DNA sequencer (Applied Biosystems, Foster City, CA) was used for sequencing utilising the PCR forward primer(s). Sequence homology was determined using BLAST (NCBI of NIH, Bethesda, MD) and Clustal W (EMBL-EBI, Heidelberg-Germany) programs.

\section{Detection of microorganisms}

Streptococcus agalactiae

Streptococcus agalactiae (group B) strains were identified from clinical samples by being weakly beta-haemolytic on Columbia CNA Agar A (Oxoid). The suspected colonies were serologically confirmed (Lancefield's classification) $[16,17]$.

\section{Chlamydia trachomatis}

endocervical swabs were tested for the presence of $C$. trachomatis using the BD ProbeTec ET Assays (BDPT, Becton Dickinson and Company, Franklin Lakes, NJ) according to the manufacturer's instructions. This method amplifies DNA from C. trachomatis in separate wells and optionally can monitor inhibition of amplification for each specimen using strand displacement amplification (SDA) and detection by fluorescent energy transfer (FRET) probes, producing a method-other-than-acceleration (MOTA) score for each specimen. Specimen processing and BDPT performance followed the manufacturer's instructions. The original algorithm involved retesting specimens with MOTA scores between 2000 and 9999. A negative repeat result (MOTA score <2000) was considered indeterminate. 


\section{Neisseria gonorrhoeae}

presumptive identification of $N$. gonorrhoeae was carried out by growth on media selective for pathogenic Neisseria species (Oxoid) incubated for up to 48 hours in 5-10\% $\mathrm{CO} 2$ at $35-37^{\circ} \mathrm{C}$. Colonies obtained were identified by API NH (bioMerieux) according to manufacturer's instructions.

\section{Mycoplasma spp}

Mycoplasma IST 2 (bioMérieux) was used for the isolation of Mycoplasma hominis and Ureaplasma urealyticum according to the manufacturer's instructions. The diagnostic kit provided information regarding the presence or absence of $M$. hominis and $U$. urealyticum and an estimate of the density of each organism (cut-off $10^{4}$-colour-changing units- $\mathrm{CCU} / \mathrm{ml}$ ) together with its antimicrobial susceptibilities to doxycycline, josamycin, ofloxacin, erythromycin, tetracycline, pristinamycin, azithromycin, clarythromycin, ciprofloxacin.

\section{Candida spp}

cervical-vaginal samples were cultured on Sabouraud dextrose agar (Oxoid) aerobically at $37^{\circ} \mathrm{C}$ for $24-48 \mathrm{~h}$ $[16,17]$. The identity of clinical isolates was confirmed by conventional mycological methods $[18,19]$, such as the germ tube induction test in serum (C. albicans or C. $d u b$ liniensis), microscopic morphology, and growth on Oxoid Chromogenic Candida Agar (Oxoid) [18].

Non-Candida albicans yeast isolates were further speciated with API 20C AUX or API 32C.

\section{Trichomonas vaginalis}

the vaginal swab was placed in $0.2 \mathrm{ml}$ of sterile physiologic saline for wet mount evaluation and examined microscopically $(400 \times)$ within $15 \mathrm{~min}$ for motile trichomonads.

The culture was carried out on Oxoid's Trichomonas Medium n. 2 for the recovery of $T$. vaginalis and incubated aerobically a $37^{\circ} \mathrm{C}$. The broth was examined microscopically for motile trichomonads on days 1,3 and 5 [16,17].

\section{Bacterial vaginosis}

the presence of bacterial vaginosis was evaluated microscopically on samples collected from the posterior vaginal fornix. Bacterial vaginosis was diagnosed by the presence of three of the clinical and microscopic findings standardized by Amsel et al [20]: vaginal pH greater than 4.5; presence of clue cells; grey homogenous vaginal discharge; positive Whiff-test in which a fishy odour is released after the addition of $10 \%$ potassium hydroxide solution to vaginal fluid.

\section{Statistical analysis}

The $\chi^{2}$ test was used in the statistical analysis, while the Odd Ratio was used to measure the strength of the association with HPV. Statistical tests were considered significant if the $\mathrm{p}$ value was 0.05 or less. Logistic regression analysis was used to assess the simultaneous effect of more than one variable on the risk of HPV infection and to identify possible confounding factors.

\section{Results \\ Study group characteristics}

Out of 857 enrolled outpatients, two groups of patients were identified on the basis of HPV DNA test positivity. The demographic and behavioural characteristics of the study population (266 HPV positive and $591 \mathrm{HPV}$ negative women) are presented in table 1 . The women were aged between 17 and 57 years (mean 32.7 years). As expected, the features significantly associated with HPVDNA detection in univariate analysis were: young patient's age; age at first intercourse; high number of lifetime sexual partners. Smokers were $29.98 \%$ in the total population with a significantly higher percentage in HPV positive group (38.1\% vs. 28.0; $\mathrm{p}=0.003)$. HPV-DNA detection was significantly higher in the nullipara women and in those without spontaneous abortion. Only $22.40 \%$ of the study participants usually use at least one contraceptive method with no significant differences in HPV positivity.

\section{HPV genotyping}

HPV genotypes found in samples from HPV positive women were shown in table 2. Thirty-five different HPV types were identified: HPV16 was the most prevalent (14.50\%), followed by HPV58 (9.16\%), HPV53 (8.01\%) and HPV42 (6.10\%); whereas each other genotype was present in less than 5\% of HPV positive women. In addition there were 4 cases of "missed typing" (1.5\%), probably due to mixed infections with different HPV genotypes. Moreover it should be considered that PCR amplification and sequencing detect precisely the more abundant (and probably clinically relevant) type and underestimate coinfections. According to the reclassification proposed by Munoz et al. (2006) [3], the aggregated percentage (HR and probably HR) of detected HPV was 58.77\%, 27.86\% for low-risk and $13.35 \%$ for unknown-risk HPV types. Of the HPV negative women, $2.3 \%$ revealed an abnormal cervical cytology (2\% LG-SIL; 0.3\% HG-SIL). Among HPV positive women more than $60 \%$ had normal cytology, whereas only $3.98 \%$ had HG-SIL. LG-SIL and ASCUS were found in $29.8 \%$ and $3.1 \%$ respectively of HPV positive women. 
Table I: Characteristics of studied groups: univariate analysis of age, sexual, reproductive and behavioural history.

\begin{tabular}{|c|c|c|c|c|c|c|c|}
\hline & $\mathrm{HPV}(+)$ & HPV(-) & Total & $\mathrm{HPV}(+) \%$ & Comparison* & $95 \% \mathrm{Cl}$ & significance \\
\hline TOTAL: frequency & 266 & 591 & 857 & $31.0 \%$ & & & \\
\hline \multicolumn{8}{|l|}{ Age } \\
\hline mean age (years) (sd) & $31.1(8.0)$ & $33.5(7.5)$ & $32.7(7.6)$ & & diff. -2.4 & -1.3 to -3.5 & $\begin{array}{l}t=-4.26 \\
P<0.00005\end{array}$ \\
\hline \multicolumn{8}{|l|}{ Frequency: } \\
\hline$<25$ years & 63 & 72 & 135 & $46.7 \%$ & $O R=1.00$ & & \\
\hline 25- years & 58 & 116 & 174 & $33.3 \%$ & $\mathrm{OR}=0.57$ & 0.36 to 0.91 & $P=0.017$ \\
\hline 30- years & 68 & 142 & 210 & $32.4 \%$ & $O R=0.55$ & 0.35 to 0.85 & $P=0.008$ \\
\hline 35- years & 36 & 144 & 180 & $20.0 \%$ & $O R=0.29$ & 0.17 to 0.47 & $P<0.00005$ \\
\hline $40+$ years & 41 & 117 & 158 & $25.9 \%$ & $O R=0.40$ & 0.25 to 0.65 & $P=0.0003$ \\
\hline \multicolumn{8}{|l|}{ Age at I st intercourse } \\
\hline mean age (years) & 18.6 & 19.6 & 19.3 & & diff. - I.0I & -0.49 to -1.54 & $\begin{array}{l}\mathrm{t}=-3.79 \\
\mathrm{P}=0.0002\end{array}$ \\
\hline \multicolumn{8}{|l|}{ Frequency: } \\
\hline$<16$ years & 25 & 42 & 67 & $37.3 \%$ & $O R=1.00$ & & \\
\hline 16 years & 34 & 55 & 89 & $38.2 \%$ & $O R=1.04$ & 0.54 to 2.00 & $P=0.91$ \\
\hline 17 years & 44 & 73 & 117 & $37.6 \%$ & $O R=1.01$ & 0.54 to 1.88 & $P=0.97$ \\
\hline 18 years & 58 & 115 & 173 & $33.5 \%$ & $O R=0.85$ & 0.47 to 1.52 & $P=0.58$ \\
\hline 19 years & 36 & 55 & 91 & $39.6 \%$ & $O R=1.10$ & 0.57 to 2.11 & $P=0.77$ \\
\hline 20 years & 21 & 87 & 108 & $19.4 \%$ & $O R=0.4 \mathrm{I}$ & 0.20 to 0.81 & $P=0.01$ \\
\hline 21 years & 15 & 24 & 39 & $38.5 \%$ & $O R=1.05$ & 0.47 to 2.37 & $P=0.91$ \\
\hline $22+$ years & 33 & 140 & 173 & $19.1 \%$ & $\mathrm{OR}=0.40$ & 0.21 to 0.74 & $P=0.004$ \\
\hline \multicolumn{8}{|l|}{ Number of partners } \\
\hline mean & 4.20 & 2.83 & 3.26 & & diff. 1.37 & 0.96 to 1.79 & $\begin{array}{l}t=6.51 \\
P<0.00005\end{array}$ \\
\hline \multicolumn{8}{|l|}{ frequency: } \\
\hline I partner & 39 & 234 & 273 & $14.3 \%$ & $O R=1.00$ & & \\
\hline 2 partners & 46 & 129 & 175 & $26.3 \%$ & $O R=2.14$ & 1.33 to 3.45 & $P<0.00005$ \\
\hline 3 partners & 58 & 86 & 144 & $40.3 \%$ & $O R=4.05$ & 2.52 to 6.51 & $P<0.00005$ \\
\hline 4 partners & 41 & 42 & 83 & $49.4 \%$ & $\mathrm{OR}=5.86$ & 3.39 to 10.13 & $P<0.00005$ \\
\hline 5-9 partners & 54 & 75 & 129 & $41.9 \%$ & $\mathrm{OR}=4.32$ & 2.65 to 7.03 & $P<0.00005$ \\
\hline $10+$ partners & 28 & 25 & 53 & $52.8 \%$ & $\mathrm{OR}=6.72$ & 3.55 to $|2.7|$ & $P<0.00005$ \\
\hline \multicolumn{8}{|l|}{ Parity } \\
\hline Nulliparous & 215 & 432 & & $33.2 \%$ & $O R=1.00$ & & \\
\hline Parous & 51 & 159 & & $24.3 \%$ & $O R=0.64$ & 0.45 to 0.92 & $P=0.0154$ \\
\hline \multicolumn{8}{|l|}{ Spontaneous abortion } \\
\hline No & 238 & 485 & 723 & $32.9 \%$ & $O R=1.00$ & & \\
\hline Yes & 28 & 106 & 134 & $20.9 \%$ & $\mathrm{OR}=0.54$ & 0.35 to 0.84 & $P=0.0063$ \\
\hline \multicolumn{8}{|l|}{ Induced abortion } \\
\hline No & 227 & 493 & 720 & $31.5 \%$ & $O R=1.00$ & & \\
\hline Yes & 39 & 98 & 137 & $28.5 \%$ & $O R=0.86$ & 0.58 tol. 29 & $P=0.48$ \\
\hline \multicolumn{8}{|l|}{ Contraceptives } \\
\hline never used any type & 210 & 455 & 665 & $31.5 \%$ & $O R=1.00$ & & \\
\hline have used at least one type & 56 & 136 & 192 & $29.2 \%$ & $O R=0.89$ & 0.63 to 1.27 & $P=0.52$ \\
\hline \multicolumn{8}{|l|}{ Smoking } \\
\hline never smoked & 168 & 432 & 600 & $28.0 \%$ & $O R=1.00$ & & \\
\hline ever smoked & 98 & 159 & 257 & $38.1 \%$ & 1.58 & 1.17 to 2.16 & $P=0.003$ \\
\hline
\end{tabular}

*diff. is the difference between two mean values and OR is the odds ratio compared with the first category.

\section{Different microorganisms infection rate}

In the total population, $C$. trachomatis was revealed in $8.05 \%$ of the samples, $U$. urealyticum was present in $28.35 \%$ and $S$. agalactiae in $8.86 \%$; T. vaginalis was found only in $1.16 \%$, bacterial vaginosis in $6.30 \%$, and yeast in $13.06 \%$.
M. hominis was isolated only in a few cases whereas $N$. gonorrhoeae was never found.

\section{Co-infection HPV-other microorganisms}

The detection of genital infections in the HPV negative population was not infrequent: in fact $S$. agalactiae was 
Table 2: Genotypes in HPV positive women.

\begin{tabular}{|c|c|c|c|c|c|c|c|c|c|c|c|c|}
\hline \multicolumn{13}{|l|}{ Risk category* } \\
\hline HIGH: & & & & & & & & & & & & total \% \\
\hline HPV type & 16 & 18 & 31 & 33 & 35 & 45 & 51 & 52 & 56 & 58 & 59 & \\
\hline Frequency & 38 & 7 & 13 & 8 & 2 & 1 & 5 & 8 & 5 & 24 & 3 & $1 \mid 443.51$ \\
\hline \multicolumn{13}{|c|}{ Probably HIGH: } \\
\hline HPV type & 53 & 66 & 68 & 73 & & & & & & & & \\
\hline frequency & 21 & 12 & 1 & 6 & & & & & & & & $40 \mid 5.27$ \\
\hline \multicolumn{13}{|l|}{ LOW: } \\
\hline HPV type & 6 & I I & 42 & 43 & 44 & 54 & 61 & 70 & 72 & 81 & 91 & \\
\hline frequency & 13 & 6 & 16 & 1 & 2 & 11 & 6 & 10 & 1 & 5 & 2 & 7327.86 \\
\hline \multicolumn{13}{|l|}{ UNKNOWN: } \\
\hline HPV type & 30 & 34 & 62 & 67 & 74 & 84 & 85 & 86 & 87 & & & \\
\hline frequency & 3 & 3 & 1 & 2 & 5 & 7 & 2 & 2 & 10 & & & 3513.36 \\
\hline
\end{tabular}

*According to Munoz et al. (2006) [3], I I types were classified as high risk, 4 types as probably high-risk; II were classified as low-risk. Nine types were grouped as unknown-risk HPV because of their incomplete characterization due to their rare detection or recent identification.

found in $9.4 \%$ of samples, yeasts in $13.5 \%$, bacterial vaginosis in 5.2\%, C. trachomatis in 5.4\% and U. urealyticum in $24.8 \%$. Generally $U$. urealyticum is a common commensal of the female lower genital tract and it seems to be an important opportunistic pathogen during pregnancy and in other genital diseases such as cervicitis. Its pathogenic potential seems to be related to the high density in the analysed samples $(>10,000 \mathrm{CCU} / \mathrm{ml})$. In HPV negative patients the percentage of $U$. urealyticum > 10,000 CCU/ $\mathrm{ml}$ was $5.24 \%$ (table 3 ).

The number of the specimens in which $T$. vaginalis was detected was very low in both populations (1.12\% in HPV positive women vs. $1.18 \%$ ).
Statistical analyses did not reveal any association between HPV presence and $S$. agalactiae, yeasts, T. vaginalis and $U$. urealyticum $<10,000 \mathrm{CCU} / \mathrm{ml}$ detection.

Although the bacterial vaginosis was diagnosed in a higher percentage among HPV positive women (8.6\% vs. $5.2 \%$ control group), the difference in the prevalence of bacterial vaginosis was not statistically significant between the 2 groups.

A significant association between HPV-DNA presence and concurrent genital infection with $C$. trachomatis $(\mathrm{p}<$ 0.001 ) was observed (table 3). Interestingly, among HPV positive women co-infected by C. trachomatis $67.56 \%$ belonged to the HR-HPV infected patients.

Table 3: Different microorganisms infection in HPV positive and negative women

\begin{tabular}{|c|c|c|c|c|c|c|c|}
\hline & $\mathrm{HPV}(+)$ & $\operatorname{HPV}(-)$ & Total & $\%$ positive & odds ratio & $95 \% \mathrm{Cl}$ & Significance \\
\hline \multicolumn{8}{|l|}{ C. trachomatis } \\
\hline negative & 229 & 559 & 788 & $29.0 \%$ & $O R=1.00$ & & \\
\hline Positive & 37 & 32 & 69 & $53.6 \%$ & $\mathrm{OR}=2.82$ & I.74 to 4.57 & $P<0.00005$ \\
\hline \multicolumn{8}{|l|}{ U. urealyticum } \\
\hline negative & 170 & 444 & 614 & $27.7 \%$ & $\mathrm{OR}=1.00$ & & \\
\hline$<10000 \mathrm{CCU} / \mathrm{ml}$ & 61 & 116 & 177 & $34.5 \%$ & $O R=1.37$ & 0.96 to 1.96 & $P=0.08$ \\
\hline$>10000 \mathrm{CCU} / \mathrm{ml}$ & 35 & 31 & 66 & $53.0 \%$ & $\mathrm{OR}=2.95$ & 1.79 to 4.85 & $P<0.00005$ \\
\hline \multicolumn{8}{|l|}{ S. agalactiae } \\
\hline negative & 246 & 535 & 781 & $31.5 \%$ & $O R=1.00$ & & \\
\hline Positive & 20 & 56 & 76 & $26.3 \%$ & $\mathrm{OR}=0.78$ & 0.46 to 1.32 & $P=0.35$ \\
\hline \multicolumn{8}{|l|}{ Yeasts } \\
\hline negative & 234 & 511 & 745 & $31.4 \%$ & $O R=1.00$ & & \\
\hline Positive & 32 & 80 & 112 & $28.6 \%$ & $O R=0.87$ & 0.56 to 1.35 & $P=0.55$ \\
\hline \multicolumn{8}{|l|}{ Bacterial vaginosis } \\
\hline negative & 243 & 560 & 803 & $30.3 \%$ & $O R=1.00$ & & \\
\hline Positive & 23 & 31 & 54 & $42.6 \%$ & $O R=1.71$ & 0.98 to 2.98 & $P=0.06$ \\
\hline \multicolumn{8}{|l|}{ T. vaginalis } \\
\hline negative & 263 & 584 & 847 & $31.1 \%$ & $\mathrm{OR}=1.00$ & & \\
\hline Positive & 3 & 7 & 10 & $30.0 \%$ & $\mathrm{OR}=0.95$ & 0.24 to 3.71 & $P=0.94$ \\
\hline
\end{tabular}


Moreover another significant association was found between the HPV positivity and the presence of $U$. urealyticum > 10,000 CCU/ml $(\mathrm{p}<0.001)($ table 3$)$.

Logistic regression analyses did not substantially change these results.

\section{Discussion}

Our findings confirm that an increased risk of HPV infection is strongly associated with a young age at first intercourse, and with an elevated number of sexual partners as would be expected for a sexually transmitted viral infection.

Epidemiological studies have demonstrated the role of other sexually transmitted infectious agents in the pathogenesis of cervical cancer, but knowledge about the specific role of these pathogens in the natural history of HPV infection is limited. There are several mechanisms by which these co-infections may act, such as direct genotoxicity, but probably the most likely biologic mechanism is the induction of cervical inflammation leading genotoxic damage through oxidative metabolites [21]. An association between cervical cancer and C. trachomatis has been established [22]. In fact, C. trachomatis infection may increase susceptibility to HPV causing microabrasions or alterations of epithelial cells thus facilitating the entry of virions. Some reports have suggested that concurrent $C$. trachomatis infection can reduce host ability to resolve HPV infection: chronic cervical inflammation seems to influence the HPV persistence through a raised production of free radicals and a reduction of host cell-mediated immunity $[2,10]$. C. trachomatis infection induces a shift in the immune response and the unresolved infections have been associated with a humoral (T helper cell type 2) immune response, whereas cellular (T helper cell type 1) immune response is important for the clearance of HPV lesions. Therefore, the modulation of cervical immune response by $C$ trachomatis may influence the clearance of HPV lesions [10].

Our data showed, in HPV positive patients, particularly in HR HPV positive women, an increased C. trachomatis infection rate; this result may suggest more accurate screening for C. trachomatis in HPV positive patients with an atypical cytology. Since both pathogens are co-variables related to sexual behaviour, probably they synergize in inducing cervical epithelium alterations $[3,23]$.

An increased infection rate of $U$. urealyticum in HPV positive group was also observed, but a significant association was found only with high density cervical presence. The biological role of $U$. urealyticum infection in the HPV outcome was not previously clarified, but high level of $U$. urealyticum seems to be a cofactor in the development of HPV related cervical dysplasia [24]. It is tempting to speculate that the presence of $U$. urealyticum may play a role both in initiating cellular anomalies and in viral persistence. It was reported that Mycoplasma infections cause in vitro chromosomal changes and cell transformation throughout gradual progressive chromosomal loss and translocations [25]. Robertsonian chromosome translocation has been identified in the presence of Mycoplasma infections [26].

Previous researches have produced conflicting results regarding the role of bacterial vaginosis as cofactor in the development of cervical intraepithelial neoplasia [27]. Thus, although bacterial vaginosis may have an influence in acquisition of genital infections, its role into HPV acquisition and persistence remains to be clarified [28]. Moreover, to date the only prospective study on bacterial vaginosis and HPV infection, showed that both infections occur simultaneously [29] and suggested that the presence of HPV may have an influence in the vaginal flora. In our findings, bacterial vaginosis is not statistically associated with HPV infection, even if alterations of vaginal flora tend to be more common among HPV positive than HPV negative women ( $8.6 \%$ vs. $5.2 \%$ respectively).

This study evidenced also the lack of protective precautions against sexually transmitted infections, both in HPV positive and HPV negative women. Despite the use of condom is not reported to be highly effective in reducing HPV transmission [30,31], counselling on sexually transmitted diseases (STDs) prevention use should be continued, for instance, to prevent C. trachomatis transmission.

\section{Conclusion}

In this study a statistically significant association between HPV and C. trachomatis was found and interestingly also with $U$. urealyticum at a high colonization rate. Although bacterial vaginosis was not significantly associated with $\mathrm{HPV}$, it was more common among HPV positive women. These data confirm that screening for genital infections may be important to reveal the simultaneous presence of different sexually transmitted microorganisms. These results suggest and emphasize the value of the screening for genital infections in HPV positive patients in order to decrease the presence of other microorganisms and to reduce the probable synergistic effects of co-infections. Prevention is important not only to avoid other STDs and their sequelae, but also to reduce the influence of concomitant microorganisms on HPV infection.

\section{Competing interests}

The authors declare that they have no competing interests.

\section{Authors' contributions}

$\mathrm{RV}, \mathrm{AP}, \mathrm{EC}$ and AMD conceived the study, collected and interpreted the data and wrote the manuscript; EM, EC and RV collected the samples and analysed the clinical 
data; JO performed the statistical analyses and drafted the manuscript; $\mathrm{RN}$ and FC carried out the bacterial analyses and contribute to draft the manuscript; MB performed the HPV DNA tests and participated in the sequence analysis with AP and AMD; GA participated to the design of the study and was involved in drafting and revising critically the manuscript; All authors read and approved the final manuscript.

\section{Acknowledgements}

This work was partially supported by grant from MIUR-Italy (Ministero dell'Università, Istruzione, Ricerca scientifica).

\section{References}

I. Schiffman MH, Castle P: Epidemiologic studies of a necessary causal risk factor: human papillomavirus infection and cervical neoplasia. J Natl Cancer Inst 2003, 95:E2.

2. Scheurer ME, Tortolero-Luna G, Adler-Storthz K: Human papillomavirus infection: biology, epidemiology, and prevention. Int J Gynecol Cancer 2005, 15:727-46.

3. Munoz N, Castellsague X, de Gonzalez AB, Gissmann L: HPV in the etiology of human cancer. Vaccine 2006, 24(S3):SI-SIO.

4. Flores R, Papenfuss M, Klimecki WT, Giuliano AR: Cross-sectional analysis of oncogenic HPV viral load and cervical intraepithelial neoplasia. Int J Cancer 2006, I I 8(5): I | 87-93.

5. Riva E, Serraino D, Pierangeli A, Bambacioni F, Zaniratti S, Minosse C, Selleri M, Bucci M, Scagnolari C, Degener AM, Capobianchi MR, Antonelli G, Dianzani F, the Roman Papillomavirus Study Group: Markers of human papillomavirus infection and their correlation with cervical dysplasia in human immunodeficiency virus-positive women. Clin Microbiol Infect 2007, I3(I):94-7.

6. Clifford GM, Goncalves MA, Franceschi S, HPV and HIV Study Group: Human papillomavirus types among women infected with HIV: a meta-analysis. AIDS 2006, 20(18):2337-44.

7. Vaccarella S, Herrero R, Dai M, Snijders PJ, Meijer CJ, Thomas JO, Hoang Anh PT, Ferreccio C, Matos E, Posso H, de Sanjosé S, Shin HR, Sukvirach S, Lazcano-Ponce E, Ronco G, Rajkumar R, Qiao YL, Muñoz $\mathrm{N}$, Franceschi S: Reproductive factors, oral contraceptive use, and human papillomavirus infection: pooled analysis of the IARC HPV prevalence surveys. Cancer Epidemiol Biomarkers Prev 2006, I 5(I I):2148-53.

8. Vaccarella S, Franceschi S, Herrero R, Muñoz N, Snijders PJ, Clifford GM, Smith JS, Lazcano-Ponce E, Sukvirach S, Shin HR, de Sanjosé S, Molano M, Matos E, Ferreccio C, Anh PT, Thomas JO, Meijer CJ, IARC HPV Prevalence Surveys Study Group: Sexual behavior, condom use, and human papillomavirus: pooled analysis of the IARC human papillomavirus prevalence surveys. Cancer Epidemiol Biomarkers Prev 2006, I5(2):326-33.

9. Verteramo R, Pierangeli A, Calzolari E, Patella A, Recine N, Mancini E, Marcone V, Masciangelo R, Bucci M, Antonelli G, Degener AM: Direct sequencing of HPV DNA detected in gynaecologic outpatients in Rome, Italy. Microbes Infect 2006, 8(9I0):2517-2I.

10. Samoff E, Koumans EH, Markowitz LE, Sternberg M, Sawyer MK, Swan D, Papp JR, Black CM, Unger ER: Association of Chlamydia trachomatis with persistence of high-risk types of human papillomavirus in a cohort of female adolescents. Am J Epidemiol 2005, I 62(7):668-75.

II. Finan RR, Musharrafieh U, Almawi WY: Detection of Chlamydia trachomatis and herpes simplex virus type I or 2 in cervical samples in human papilloma virus (HPV)-positive and HPVnegative women. Clin Microbiol Infect 2006, I 2(9):927-30.

12. Smith JS, Herrero R, Bosetti C, Muñoz N, Bosch FX, Eluf-Neto J, Castellsagué X, Meijer CJ, Brule AJ Van den, Franceschi S, Ashley R, International Agency for Research on Cancer (IARC) Multicentric Cervical Cancer Study Group: Herpes simplex virus-2 as a human papillomavirus cofactor in the etiology of invasive cervical cancer. J Natl Cancer Inst 2002, 94(2I):1604-13.

13. Solomon D: The Bethesda System for reporting cervical/vaginal cytologic diagnosis: an overview. Int J Gynecol Pathol |991, 10:323-325.
14. Bernard HU, Chan SY, Delius H: Evolution of Papillomaviruses. Curr Top Microbiol Immunol 1994, 186:33-54.

15. Sasagawa T, Minemoto Y, Basha W, Yamazaki H, Nakamura M, Yoshimoto H, Sakaike J, Inoue M: A new PCR-based assay amplifies the E6-E7 genes of most mucosal human papillomaviruses. Virus Res 2000, 67:127-139.

16. Ruoff KL, Whiley RA, Beighton D: Streptococcus. In Manual of Clinical Microbiology 7th edition. Edited by: Murray EJ, Baron MA, Pfaller FC, Tenover RH, Yolken PR. Washington DC: ASM Press; 1999:283-305

17. Morven SE, Baker CJ: Streptococcus agalactiae. In Practice of Infectious Diseases Volume 2. Edited by: Mandell GL, Bennett JE. R Dolin Churchill Livingstone/Harcourt Brace, Philadelphia/London; 2000:2156-2167.

18. Houang ET, Chu KC, Koehler AP, Cheng AF: Use of CHROMagar Candida for genital specimens in the diagnostic laboratory. J Clin Pathol 1997, 50(7):563-5.

19. Freydiere AM, Guinet R, Boiron P: Yeast identification in the clinical microbiology laboratory: phenotypical methods. Med Mycol 200I, 39(I):9-33.

20. Amsel R, Totten PA, Spiegel CA, Chen KC, Eschenbach D, Holmes KK: Nonspecific vaginitis: Diagnostic criteria and microbial and epidemiologic associations. Am J Med 1983, 74:14-22.

21. Castle PE, Giuliano AR: Genital tract infections, cervical inflammation, and antioxidant nutrients-assessing their roles as human papillomavirus cofactors. J Natl Cancer Inst Monogr 2003 , 3I:29-34.

22. Smith JS, Bosetti C, Muñoz N, Herrero R, Bosch FX, Eluf-Neto J, Meijer CJ, Brule AJ Van Den, Franceschi S, Peeling RW, IARC multicentric case-control study: Chlamydia trachomatis and invasive cervical cancer: a pooled analysis of the IARC multicentric case-control study. Int J Cancer 2004, I I I (3):43 I-9.

23. Palefsky JM, Holly EA: Immunosuppression and co-infection with HIV. J Natl Cancer Inst Monogr 2003, 31:41-6.

24. Lukic A, Canzio C, Patella A, Giovagnoli M, Cipriani P, Frega A, Moscarini : Determination of cervicovaginal microorganisms in women with abnormal cervical cytology: the role of Ureaplasma urealyticum. Anticancer Res 2006, 26(6C):4843-9.

25. Macpherson I, Russell W: Transformations in hamster cells mediated by mycoplasmas. Nature 1966, 21 0:1343-5.

26. Tsai S, Wear DJ, Shih JW, Lo SC: Mycoplasmas and oncogenesis: persistent infection and multistage malignant transformation. Proc Natl Acad Sci USA 1995, 92:10197-201.

27. Boyle DC, Barton SE, Uthayakumar S, Hay PE, Pollock JW, Steer PJ, Smith JR: Is bacterial vaginosis associated with cervical intraepithelial neoplasia? Int J Gynecol Cancer 2003, I3(2): I59-63.

28. Watts DH, Fazzari M, Minkoff $H$, Hillier SL, Sha B, Glesby M, Levine AM, Burk R, Palefsky JM, Moxley M, Ahdieh-Grant L, Strickler HD: Effects of bacterial vaginosis and other genital infections on the natural history of human papillomavirus infection in HIV-I-infected and high-risk HIV-I-uninfected women. Infect Dis 2005, I 9 I(7): I I29-39.

29. Mao C, Hughes JP, Kiviat N, Kuypers J, Lee SK, Adam DE, Koutsky LA: Clinical findings among young women with genital human papillomavirus infection. Am J Obstet Gynecol 2003, 188:677-84.

30. Winer RL, Hughes JP, Feng Q, O'Reilly S, Kiviat NB, Holmes KK, Koutsky LA: Condom use and the risk of genital human papillomavirus infection in young women. N Engl J Med 2006, 354:2645-54.

31. Shew ML, Fortenberry JD, Tu W, Juliar BE, Batteiger BE, Qadadri B, Brown DR: Association of condom use, sexual behaviors, and sexually transmitted infections with the duration of genital human papillomavirus infection among adolescent women. Arch Pediatr Adolesc Med 2006, 160(2):15I-6.

\section{Pre-publication history}

The pre-publication history for this paper can be accessed here:

http://www.biomedcentral.com/1471-2334/9/16/prepub 